\title{
Effect of Extraction and Adsorption on Re-refining of Used Lubricating Oil
}

\author{
A. Kamal ${ }^{1}$ and F. Khan ${ }^{2}$ \\ 1 Department of Applied Chemistry \& Chemical Technology, University of Karachi, 75270, Karachi - Pakistan \\ 2 Department of Chemical Tech./Eng., University of Karachi, 75270, Karachi - Pakistan \\ e-mail: ashrafkamal@uok.edu.pk - fasihullahk@uok.edu.pk
}

Résumé - Effet de l'extraction et de l'adsorption sur le retraitement des huiles usagées L'extraction par solvant suivie d'adsorption est considérée comme l'un des procédés les plus performants pour le recyclage des huiles usagées. Dans cet article, la performance de divers solvants pour la formation de boues a été étudiée. Le 1-butanol produit le plus de boues, suivi de la méthyle éthyle cétone (MEK), puis du 1-hexanol et du 2-butanol. La différence de formation des boues n'est que de 0,3\% entre le 1-butanol et le MEK. Cependant, en raison de son faible point d'ébullition et de son faible coût, le MEK a été préféré au 1-butanol. L'huile extraite est ensuite passée à travers une colonne de différents adsorbants. Une huile d'indice de couleur 2 (jaune), à $0,14 \%$ de résidu de carbone, $0,02 \%$ de cendres sulfatées et $216{ }^{\circ} \mathrm{C}$ de point d'éclair, a été obtenue avec $94 \%$ de rendement.

Abstract - Effect of Extraction and Adsorption on Re-refining of Used Lubricating Oil - Solvent extraction followed by adsorption has been found to be one of the competitive processes for recycling of waste lubricating oil. In this paper, the performance of various solvents for sludge formation has been studied. 1-butanol produced maximum sludge followed by methyl ethyl ketone (MEK), 1-hexanol and 2-butanol. The difference in sludge formation between 1-butanol and MEK was only $0.3 \%$. However due to low boiling point and low cost, MEK was preferred over 1-butanol. The extracted oil was then passed through a column of different adsorbents. An oil of colour index (yellow) 2, carbon residue 0.14\%, sulphated ash $0.02 \%$ and flash point $216^{\circ} \mathrm{C}$, was obtained with $94 \%$ yield. 


\section{INTRODUCTION}

With increasing number of vehicles the volume of used lubricating oil produced each year is also increasing. The used oil contains water, salt, broken down additive components, varnish, gum and other materials. A small part of this finds its way to recovery process while the major portion is used in ways which are harmful for environment.

Recycle of used oil has been carried out by several methods. Concentrated sulphuric acid has been used to remove asphaltenic material. The product is then clay treated [1]. The sludge could be used as fuel which leads to the production of acidic gases. Use of acid could be avoided by treating used oil with natural polymers. The product is vacuum distilled then decolourized [2]. The recycled oil contains higher amount of metals.

Inorganic membrane has been used to extract the oil followed by adsorption which requires high pressure and specialized inorganic composite membrane [3]. Use of radiations has been reported [4]. Alkali $(\mathrm{NaOH} / \mathrm{KOH})$ with ammonium salt or ethylene glycol has been used to recover the oil [5-7].

Solvent extraction has been proposed as an alternate method $[8,9]$. Solvent chosen should have maximum solubility for base oil and minimum for additives and carbonaceous matter. Super critical fluids propane and ethane have also been used as extracting solvents giving low yield 72-80\% $[10,11]$. Solvent could be recovered by distillation $[12,13]$. Martins used a mixture of polar solvents in presence of potassium hydroxide [14]. Recently, used oil has been re-refined by thin film distillation under high vacuum followed by clay treatment or hydro treatment $[15,16]$.

The present work aims at finding a complete recycling process which could also be industrially feasible. The first part of the work is based on searching a cheap solvent which can reduce sludge concentration in used oil to a minimum level with higher recovery. The second part deals with adsorbent which can produce an oil having properties comparable with base oil.

\section{EXPERIMENTAL}

\subsection{Materials Used}

Used motor lubricating oil was stored for several days to allow large suspended particles to settle under gravity.

Solvents used for extraction were $n$-heptane, $n$-hexane, methyl iso butyl ketone (MIBK), MEK, 1-butanol, 2-butanol, benzene and 1-hexanol. The solvents were of analytical grade and supplied by E. Merck.

Adsorbents used were alumina and silica gel (column chromatography grade), supplied by E. Merck and local magnesite rock. Sorbents (alumina and silica gel) of particle size 70-230 mesh were used. Magnesite in variable particle sizes $16-50,50-100,70-230$ and 100-230 were tested.

\subsection{Extraction Process}

A mixture of solvent and used lubricating oil was shaken in a $100 \mathrm{ml}$ separating funnel to ensure adequate mixing. Solvent to oil ratio was $3: 1(\mathrm{v} / \mathrm{v})$. The sludge was allowed to settle at a constant temperature of $35^{\circ} \mathrm{C}$ in a thermostatic bath. After 24 hours, solvent-oil solution was separated from sludge. The sludge was dispersed twice with the same solvent to extract any remaining oil. The sludge was then dried till constant weight at $105^{\circ} \mathrm{C}$. The washing solvent was mixed with solvent-oil solution. The solvent was recovered by vacuum distillation. The yield of oil was calculated on the basis of initial mass of used oil taken.

To determine optimum conditions solvent-oil ratio, temperature and settling time were varied.

\subsection{Decolourization/Adsorption}

The extracted oil was decolourized by passing through adsorbent filled column. Types and particle size of adsorbent, adsorbent to oil ratio, types of solvent and solvent to oil ratio through column were varied.

The solvent-oil solution was distilled under vacuum and the recovered oil was dried in a vacuum dryer.

\subsection{Analysis of Used, Extracted and Adsorbed Oil}

Total Base Number (TBN), Total Acid Number (TAN), carbon residue, viscosities at 40 and $100^{\circ} \mathrm{C}$ were determined according to ASTM D 2896, D 974, D 189 and D 445 respectively. Colour was found using Lovibond (D 1500) and flash point by Cleveland Open Cup (D 92).

\section{RESULTS AND DISCUSSION}

\subsection{Selection of Solvent}

The solvents were selected according to Burrel's classification i.e. solvents with high capacity (alcohols), moderate capacity (ketones) and low capacity (hydrocarbons). Use of these solvents is based on their capacity to form hydrogen bond [17].

Results indicate that no sludge formation takes place when hydrocarbons and MIBK were used. 2-butanol formed two liquid phases at room temperature $\left(35^{\circ} \mathrm{C}\right)$ after 24 hours settling. Efficiency for sludge removal capability of 1-butanol, MEK and 1-hexanol is 1st, 2nd and 3rd respectively Figure 1. This is in agreement with the findings of Onukwli et al. [18] and Alves dos Reis and Jeromino [19]. 


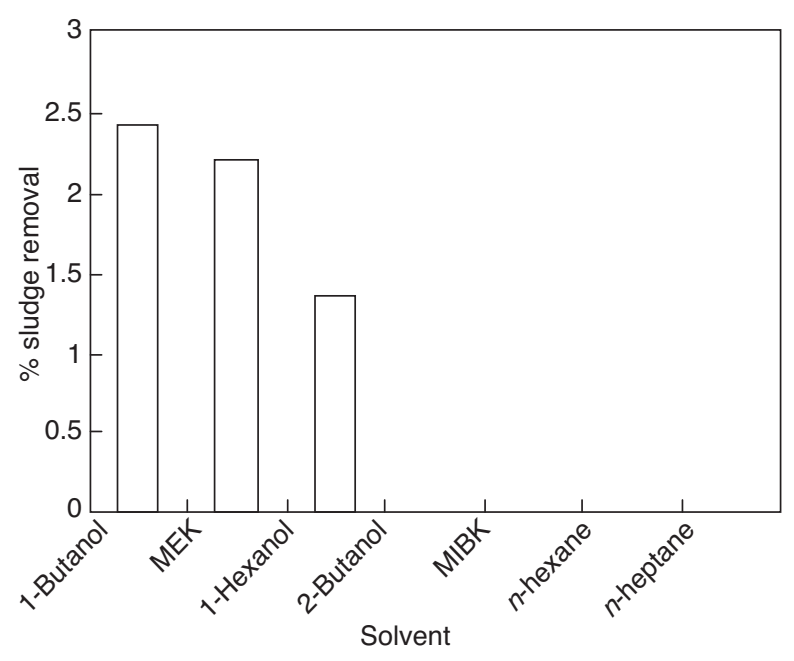

Figure 1

Sludge removal efficiency of solvents from used lubricating oil after 24 hour settling at room temperature $\left(35^{\circ} \mathrm{C}\right)$ and solvent to oil ratio $3: 1$.

Used lubricating oil is a complex mixture of recoverable base oil, polymeric additives, water, light hydrocarbons, metals and carbonaceous particles. A good extraction-flocculation solvent should dissolve base oil and precipitate other substances to form sludge. 1-butanol, MEK and 1-hexanol behave as efficient extraction-flocculation solvents for used oil due to their good solubility parameters for base oil and good antisolvent effect for nonpolar or slightly polar polymeric additives, metals and carbonaceous particles.

On comparing properties of used and extracted oil (Table 1) it is clear that specific gravity, carbon residue and \% yield decrease with increasing sludge formation capabilities of solvents. The same trend is present in viscosity values at 40 and $100^{\circ} \mathrm{C}$. Lowering of viscosity index (VI) value indicates that the solvents precipitate out the non-metallic polymeric VI improvers. 1-butaol has the best performance to remove these additives while MEK has the least. Sulphated ash value shows the presence of metallic impurities which is reduced by $45-55 \%$ in extracted oil. Total base number of oil extracted by 1-butanol and MEK is nil showing that complete removal of basic character constituents (amino compounds, salts of weak acids, basic salts of polyacidic bases, and salts of heavy metals). Using 1-hexanol the base number is reduced by almost half present in used oil. Total acid number is also reduced significantly indicating that organic and inorganic acids, esters, phenolic compounds, lactones; resins etc. have been separated out satisfactorily. The used oil contains traces of fuel which lowers the flash point. The increased flash point is an indication that the extracted oil is free of fuel and solvent.

Due to low cost and low boiling point and ease of recovery, MEK was chosen for further study.

\subsection{Effect of Settling Time}

Amount of sludge removal increases by increasing settling time. Rate of settling was maximum during initial 12 hours. However it continued up to 24 hours. Impurities aggregate and form sludge which sediments out. Further increase in time has negligible effect on sludge settling (Fig. 2).

\subsection{Sludge Formation as a Function of Temperature and Solvent / Oil Ratio}

Amount of sludge removal increases by increasing solvent to oil ratio and by decreasing temperature as indicated in Figure 3. Sludge formation remains independent of solvent to oil

TABLE 1

Properties of used and solvent extracted oil at $35^{\circ} \mathrm{C}$ at solvent to oil ratio $3: 1$ after 24 hours settling

\begin{tabular}{|c|c|c|c|c|}
\hline \multirow{2}{*}{ Property } & \multirow{2}{*}{ Used oil } & \multicolumn{3}{|c|}{ Extracted oil using } \\
\hline & & 1-butanol & MEK & 1-hexanol \\
\hline Specific gravity at $35^{\circ} \mathrm{C}$ & 0.887 & 0.884 & 0.885 & 0.886 \\
\hline Viscosity at $40^{\circ} \mathrm{C}$ (cst) & 104.75 & 65.2 & 71.5 & 72.5 \\
\hline Viscosity at $100^{\circ} \mathrm{C}$ (cst) & 13.94 & 8.72 & 9.59 & 9.67 \\
\hline Viscosity index & 128 & 113.6 & 119 & 118.6 \\
\hline Sulphated ash (wt $\%)$ & 0.9 & 0.4 & 0.4 & 0.49 \\
\hline Total base number (mg HCl/g oil) & 4.64 & Nil & Nil & 2.41 \\
\hline Total acid number (mg KOH/g oil) & 2.07 & 1.41 & 1.2 & 1.35 \\
\hline Carbon residue (wt $\%$ ) & 1.724 & 0.91 & 0.93 & 0.98 \\
\hline Colour (ASTM D 1500) & $>8$ & $>8$ & $>8$ & $>8$ \\
\hline Flash point $\left({ }^{\circ} \mathrm{C}\right)$ & 190 & 214 & 220 & 212 \\
\hline Yield (\%) & - & 97.3 & 97.6 & 98.4 \\
\hline
\end{tabular}




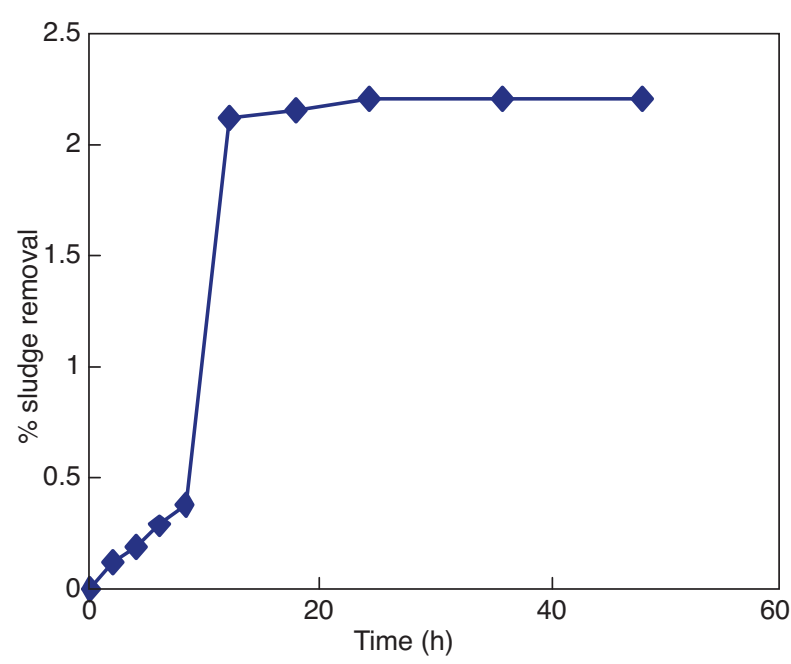

Figure 2

Effect of settling time on sludge removal by MEK at $35^{\circ} \mathrm{C}$ and solvent to oil ratio $3: 1$.

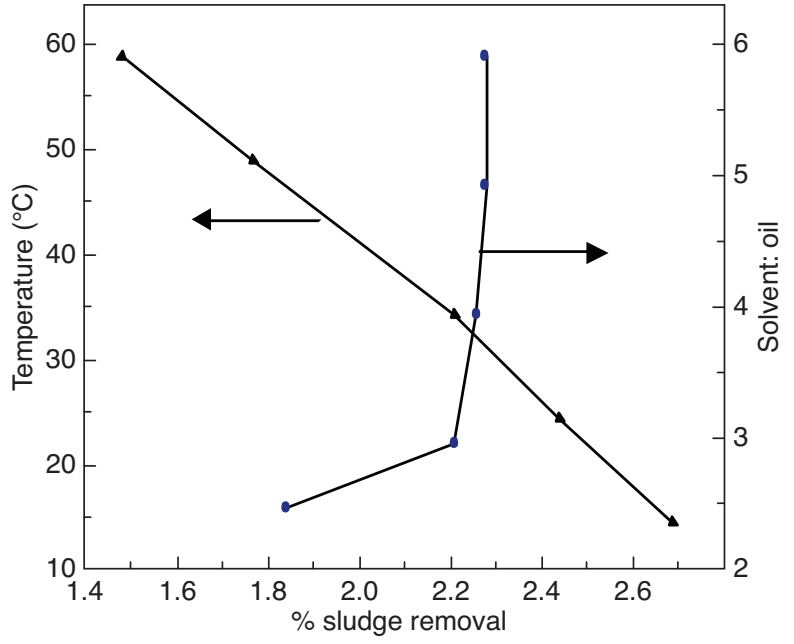

Figure 3

Sludge formation as a function of temperature and solvent to oil ratio after 24 hours settling. ratio greater than $3: 1$ which continuous to increase with decreasing temperature. The point of intersection of both trends shows that the optimum solvent to oil ratio and temperature are about 3.8 and $33^{\circ} \mathrm{C}$ respectively for sludge settling without centrifugation. However, critical clarifying ratio (CCR) for MEK has been reported as 2.6 at $35^{\circ} \mathrm{C}$ [19] with minimum oil remaining in sludge [20]. Perhaps the difference is due to free sedimentation instead of centrifugation.

At lower solvent to oil ratio, solvent becomes saturated by base oil resulting in reduced oil recovery while at higher solvent/oil ratio maximum oil could be extracted and oil free sludge is obtained. With increasing temperature, not only the oil yield but also the solubility of sludge in solvent goes on increasing which results in oil of poorer quality with reduced sludge formation. This coincides with the findings of Jesusa et al. [21] and Alves dos Reis and Jeromino (1988) respectively.

\subsection{Decolourization/Adsorption}

Column chromatography technique was used to decolourize the dark coloured MEK-extracted oil. In this regard, different variables such as, type and particle size of sorbent, activation temperature and duration, loss of sorbent mass on heating, type of eluting solvent and elution time were studied to obtain good quality oil with maximum yield.

\subsection{Choice of Sorbent}

Effect of two well known sorbents alumina and silica gel and possible use of indigenous magnesite rock for decolourization

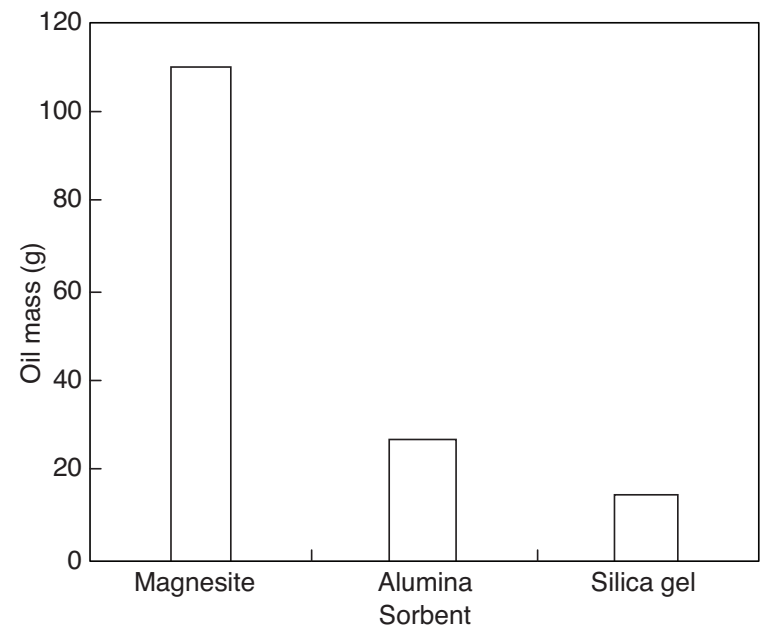

Figure 4

Mass of oil passed over $100 \mathrm{~g}$ of different sorbents. (Particle size 70-230, solvent/oil 3:1, elution time $1 \mathrm{~h}$ ).

of extracted oil were studied. $n$-hexane was used as an eluting solvent. Alumina and silica gel both are porous materials with active surface which have ability to adsorb different colouring substances [22]. Magnesite rock attains similar property on heating to $500^{\circ} \mathrm{C}$.

Figure 4 compares the decolourizing capability of these sorbents. Magnesite gave the best result, decolourizing the maximum amount of extracted oil to pale yellow (C.I. yellow 2). The column was then eluted with isopropanol, a highly polar solvent. Evaporation of the solvent under 
vacuum gave a coloured, sticky and gummy material. A mixture of high molecular mass polymeric additives and resinous compounds which did not settle out completely during flocculation and sedimentation process was obtained.

Surface area of magnesite $\left(100-150 \mathrm{~m}^{2} / \mathrm{g}\right)$ is smaller than the surface area of alumina $\left(300-350 \mathrm{~m}^{2} / \mathrm{g}\right)$ and silica gel $\left(750-800 \mathrm{~m}^{2} / \mathrm{g}\right)$. Alumina and silica gel are unable to absorb the resinous material and it soon starts to elute, while magnesite because of its bigger pore size can trap the colouring material. This results in decolourized product. However when the loading is increased to $110 \mathrm{~g}$ of oil / $100 \mathrm{~g}$ of sorbent the magnesite becomes saturated with colouring material.

Due to low cost, easy availability in all particle size and the best adsorbing performance, magnesite was chosen as sorbent for further study.

\subsection{Comparison of Solvent}

Elution was carried with three solvents of different polarities n-hexane (non-polar), benzene (less polar) and MEK (intermediate polar).

$n$-hexane can reduce colour to a very low level at lower loading of extracted oil. With increased loading its performance was still better than others. However it failed to decolourize when $100 \mathrm{~g}$ of extracted oil was introduced on $100 \mathrm{~g}$ of sorbent. MEK's performance remained constant over wide variation of extracted oil loading Figure 5.

Saturated hydrocarbons being less polar than other constituents of oil, will have less affinity for the stationary phase and elute first when hexane (polarity 0.0) is used. However on increasing amount of oil the stationary phase is overloaded and saturates together with other components pass out partially absorbed thereby increasing the colour index. As a general rule, high polar solutes are held strongly with adsorbent which can be eluted by high polar solvent [23]. When the oil is eluted with benzene (polarity 0.32 ) the colour of resulting oil deepens without increase in yield. Using MEK (polarity 0.51) the colour further deepens and the yield slightly increases as some polar compounds are also eluted.

On comparing properties of extracted and recovered oil (Table 2) it is clear that column chromatography is a good technique for the removal of impurities from extracted oil which enhances desired properties for quality lubricating oil. $n$-hexane qualifies first with respect to specific gravity, viscosity index, sulphated ash, and carbon residue and colour index. Benzene and MEK also give satisfactory results.

Since $n$-hexane is a low cost and low boiling point solvent and also gives better result especially up to moderate loading so it was chosen as an eluting solvent for further study. The oil loading was restricted to $75 \mathrm{~g}$ per $100 \mathrm{~g}$ of sorbent.

\subsection{Elution Time versus Sorbent Amount}

In this study, magnesite was used as a sorbent for adsorption of extracted oil. On activation at $500^{\circ} \mathrm{C}$ for 1,2 and 3 hours; $\%$ mass lost was $26.5 \pm 1,39.5 \pm 1$ and $49.5 \pm 1$ respectively. Evolution of water due to heating increases the surface area of magnesite which leads to the development of micro pores. The efficiency of magnesite as colour absorbing material increases accordingly.

Oil loading could also be increased by increasing residence time of eluting material. This effect is more prominent for solid activated for 3 hours Figure 6.

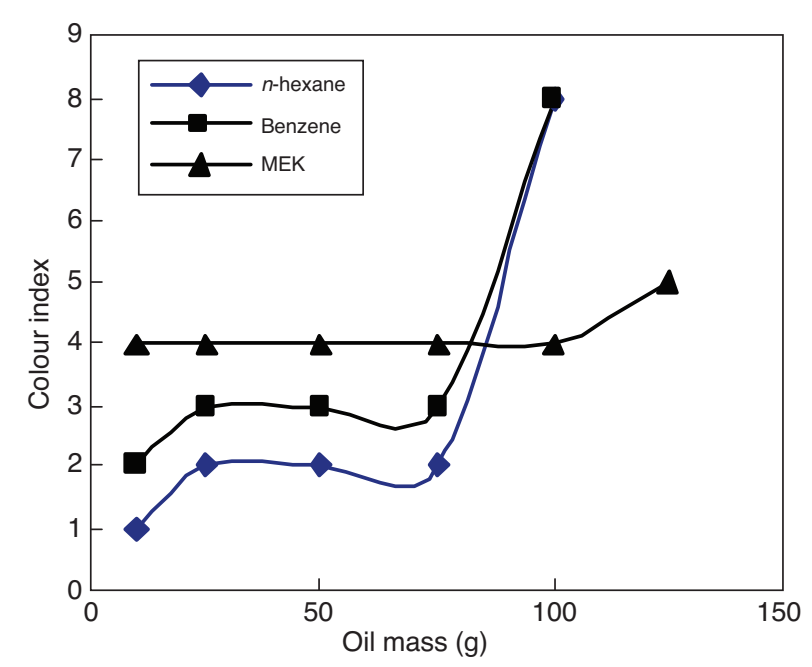

Figure 5

Mass of oil adsorbed using different solvents over $100 \mathrm{~g}$ of sorbent. (Particle size 50-100, solvent/oil 3:1, elution time $1 \mathrm{~h}$ ).

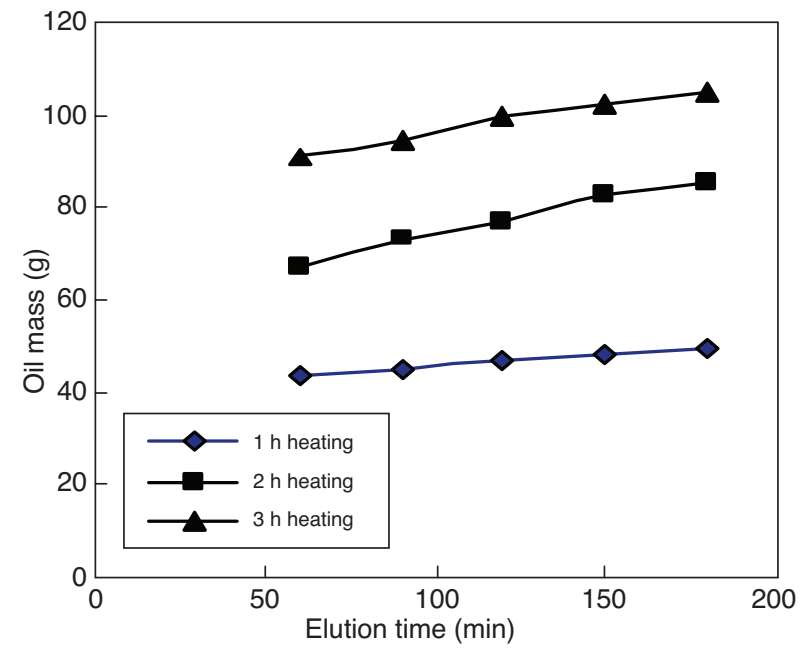

Figure 6

Mass of extracted oil passed over $100 \mathrm{~g}$ of magnesite (50-100 mesh). 
TABLE 2

Properties of recovered oil by column chromatography using different solvents as mobile phase, solvent to oil ratio is $3: 1$

\begin{tabular}{|c|c|c|c|c|}
\hline \multirow{2}{*}{ Property } & \multirow{2}{*}{$\begin{array}{c}\text { Extracted oil using } \\
\text { MEK }\end{array}$} & \multicolumn{3}{|c|}{ Recovered oil by column chromatography using } \\
\hline & & $n$-hexane & Benzene & MEK \\
\hline Specific gravity at $35^{\circ} \mathrm{C}$ & 0.885 & 0.875 & 0.881 & 0.881 \\
\hline Viscosity at $40^{\circ} \mathrm{C}$ (cst) & 71.5 & 67.55 & 67.02 & 66.85 \\
\hline Viscosity at $100^{\circ} \mathrm{C}$ (cst) & 9.59 & 8.53 & 8.37 & 8.42 \\
\hline Viscosity index & 119 & 104 & 101 & 104 \\
\hline Sulphated ash (wt\%) & 0.4 & 0.014 & 0.018 & 0.022 \\
\hline Total base number (mg HCl/g oil) & Nil & Nil & Nil & Nil \\
\hline Total acid number (mg KOH/g oil) & 1.2 & Nil & Nil & Nil \\
\hline Carbon residue (wt\%) & 0.93 & 0.14 & 0.142 & 0.146 \\
\hline Colour (ASTM D 1500) & $>8$ & 2 & 3 & 4 \\
\hline Flash point $\left({ }^{\circ} \mathrm{C}\right)$ & 220 & 216 & 216 & 218 \\
\hline Yield $(\%)$ & 97.6 & 95 & 95 & 96 \\
\hline
\end{tabular}

\subsection{Effect of Particle Size}

Particle size of a sorbent is an important factor of column chromatography. Four different particle sizes were tested. Smaller particle size gives larger surface area which favours larger amount of material to be adsorbed. Hence with larger particle size the loading of oil is very restricted due to voids and uneven packing. Figure 7 indicates that 100-230 mesh of magnesite gave the best result regarding maximum amount of oil recovered with colour index 2. Particle size smaller than 100-230 choked the column.

Experiments were repeated with industrial grade chemicals and reproducible results were obtained.

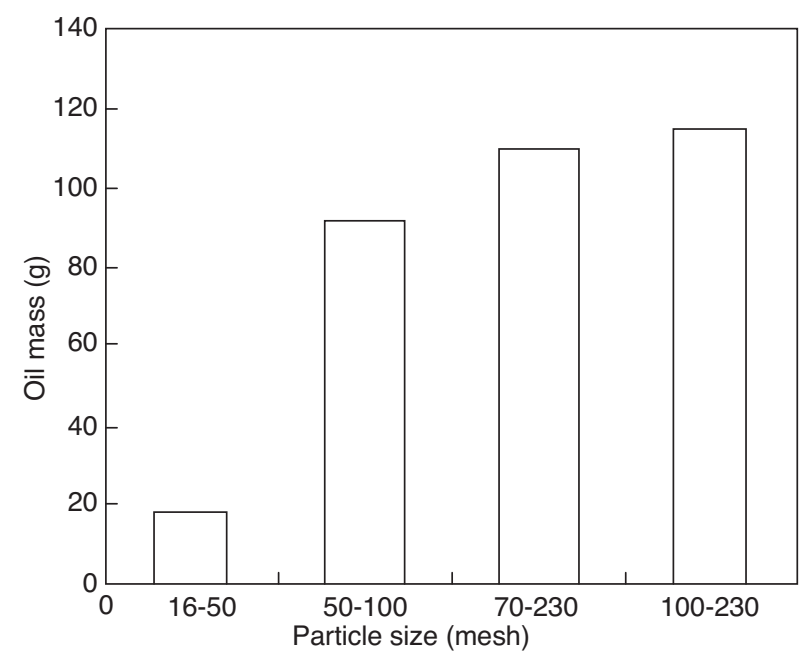

Figure 7

Mass of oil passed over $100 \mathrm{~g}$ of sorbent using different particle size.

(Mass lost 49.5 $\pm 1 \%$, solvent/oil 3:1, elution time $1 \mathrm{~h}$ ).

\section{CONCLUSION}

The findings of this study can be used to recover quality base oil with $94 \%$ yield from used lubricating oil. The yield is higher than thin film distillation/clay treatment (70-80\%) and KTI as well as Mohawk process $(82 \%)$ [24, 25]. Some modifications of thin film has claimed $90-95 \%$ oil recovery. Moreover these processes are expensive and require skilled operations [24].

Solvent extraction of used oil can be carried out at ambient temperature with cheap and low boiling point solvent MEK If the sludge is allowed to sediment out the solvent to oil ratio is 3.8 while mechanical centrifuge can reduce this ratio to 2.6 [19]. In the present study to eliminate the use of mechanical centrifuge the ratio has been maintained at 3.8 at which free sedimentation occurs. The sludge from this process can be mixed with asphalt without any problem. It is a better process than the traditional acid/clay treatment which produces an acidic sludge.

Pale yellow oil (colour index 2) is obtained by treating the extracted oil with magnesite, an indigenous cheap rock which is available in varying particle size. Gummy material and residual solvent associated with adsorbent both are incinerated during regeneration of adsorbent at $500^{\circ} \mathrm{C}$. The adsorbent could be repeatedly regenerated with reproducible results.

Extraction by MEK followed by adsorption on magnesite using $n$-hexane gives the lowest colour index oil (C.I. 2). This system however uses two solvents and thus require two solvent recovery steps. If both extraction and elution are carried out by MEK it would reduce solvent recovery step to 1 . However the oil produced has a colour index of 4.

The present work due to recoverable and cheap solvents and adsorbent could be industrially feasible. This motivates to evaluate costing of the process for future work. 


\section{ACKNOWLEDGMENT}

One of the authors (Ashraf Kamal) would like to thank Faculty of Science for research grant and University of Karachi for study leave.

\section{REFERENCES}

1 Fung D.T., Laberge J.G.J., Przystal F.S. (1978) Process for the reclamation of waste hydrocarbon oils, US Patent 4,124,492.

2 Wolk R.H. (1976) Refining of waste lube oil to prepare usable lubestock, US Patent 3,980,551.

3 Ciora J.R.J., Liu P.K.T. (2000) Refining of used oils using membrane-and adsorption-based processes, US Patent $6,024,880$.

4 Zykina R.F., Zaykin Y.A. (2002) Radiation technologies for production and regeneration of motor fuel and lubricants, Radiat. Phys. Chem. 65, 169-172.

5 Williams M.R., Krzykawski J. (2001) Method for obtaining base oil and removing impurities and additives from used oil products, US Patent 6,174,431.

6 Sherman J.H., Taylor R.T., Hofacker A.L., Hershberger J.W., Conn G.M., Gorman W.A. (2005) Method of removing contaminants from petroleum distillates, US Patent 6,929,737.

7 Sherman J.H., Taylor R.T. (2007) Method of removing contaminants from used oil, US Patent 7,267,760.

8 Whisman M.L., Goetzinger J.W., Cotton F.O. (1978) Method for reclaiming waste lubricating oils, US Patent 4,073,720.

9 Fletcher L.C., Beard H.J., O’Blasny R. (1982) Distillation and solvent extraction process for rerefining used lubricating oil, US Patent 4,360,420.

10 Rincon J., Canizares P., Garcia M.T., Garcia I. (2003) Regeneration of used lubricant oil by propane extraction, Ind. Eng. Chem. Res. 42, 4867-4873.

11 Rincon J., Canizares P., Garcia M.T. (2007) Regeneration of used lubricant oil by ethane extraction, J. Supercrit. Fluid. 39, 315-322.

12 Hamad A., Al-Zubaidy E., Fayed M.E. (2005) Used lubricating oil recycling using hydrocarbon solvents, J. Environ. Manage. 74, 153-159.
13 Haydock F.J. (2002) Method of reclaiming used motor oil for further use, US Patent 6,395,166.

14 Martins J.P. (1997) The Extraction-flocculation re-refining lubricating oil process using ternary organic solvents, Ind. Eng. Chem. Res. 36, 3854-3858.

15 Ashton W.L. (1996) Materials of the Interline Hydrocarbons, Alpine, Utah 84004, USA (provided by the author).

16 Kalnes T.N., Youtsey K.J., James R.B., Hedden D.R. (1989) Recycling waste oils for profit (UOP Direct Hydrogenation Process), Hazard. Waste Hazard. Mater. 6, 51-66.

17 Burrell H. (1955) The Challenge of Solubility Parameter Concept, J. Paint Technol. 40, 1968.

18 Onukwuli O.D., Ude B.C., Ekumankama E.O., Okeke S.I. (1999) Solvent refining of waste locomotive oil, Petrol. Sci. Technol. 17, 1-2, 15-35.

19 Reis M.A., Jeromino M.S. (1988) Waste lubricating oil rerefining by extraction-flocculation. 1. A scientific basis to design efficient solvents, Ind. Eng. Chem. Res. 27, 12221228 .

20 Elbashir N.O., Al-Zahrani S.M., Abdul Mutalib M.I., Abasaeed A.E. (2002) A method of predicting effective solvent extraction parameters for recycling of used lubricating oils, Chem. Eng. Process. 41, 765-769.

21 Rincon J., Canizares P., Garcia M.T. (2005) Regeneration of used lubricant oil by polar solvent extraction, Ind. Eng. Chem. Res. 44, 4373-4379.

22 Bauer H.H., Christian G.D., O'Reilly J.E. (1978) Solid and Liquid Phase Chromatography, in Instrumental Analysis, Allyn \& Bacon Inc, Boston.

23 Sewell P.A., Clarke B. (1987) Classical Column Chromatography, in Chromatographic Separation, John Wiley \& Sons, New York.

24 Mortier R.M., Orszulik S.T. (1992) Lubricants and their environmental impact, in Chemistry and Technology of Lubricants, Blackie Academic \& Profession, London.

25 Oosterkamp P.F.V.D. (1992) KTI Re-refining Technology, Paper presented at UNIDO sponsored Workshop, Karachi, Pakistan.

Final manuscript received in September 2008 Published online in February 2009 